\title{
Positive cross-cultural psychology: Exploring similarity and difference in constructions and experiences of wellbeing
}

\author{
Tim Lomas
}

\begin{abstract}
Critical theorists have accused positive psychology of paying insufficient attention to cultural variation in the way wellbeing is constructed and experienced. While there may be some merit to this claim, the field has developed a more nuanced appreciation of culture than its critics suggest. However, it could also be argued that positive psychology has not sufficiently appreciated or absorbed the wealth of literature within cross-cultural psychology pertaining to wellbeing. This paper aims to forge a bridge between positive psychology and cross-cultural psychology by introducing the idea of 'positive cross-cultural psychology,' an interdisciplinary conceptual space for existing and future cross-cultural research on wellbeing. Moreover, the paper offers a meta-theoretical perspective on trends within this literature. It is suggested that crosscultural research is underpinned by two broad orienting perspectives: a 'universalising' perspective, which holds that, despite apparent cultural differences, people share a common human nature; and a 'relativising' perspective, which argues that people are strongly shaped by their cultural context. However, the paper finally argues that most research can actually be seen as offering a synthesising perspective - labelled here as 'universal relativism' - which recognises universals in the ways wellbeing is sought, constructed and experienced, but allows for extensive variation in the ways these universals are shaped by culture.
\end{abstract}

Keywords: cross-cultural; culture; universalism; relativism; wellbeing

\section{Introduction}

As positive psychology (PP) took shape in the early years of the $21^{\text {st }}$ century, one of the most prominent criticisms of this nascent field concerned its presumptions of universality. Scholars in the area were without doubt making pioneering efforts towards examining and elucidating constructs pertaining to happiness and wellbeing. However, almost without exception, these scholarly efforts were under the auspices of universities in North America, and other areas of the Western world. This fact of culture and geography of course does not undermine any of the research and theorising undertaken there, except in one respect: it places limits on the extent to which one might deem the constructs identified in these locations to be universal. The trouble, from a critical perspective, was that much of the work undertaken in PP did appear to make this presumption of universality (Wierzbicka, 2004). Concepts that had been identified mainly through testing affluent American undergraduate students tended to be presented as if universally applicable across time and place, generalizable to all other peoples and cultures. This is not a tendency to which only PP is susceptible; arguably it is the default setting of most mainstream psychology. Nevertheless, it was problematic, presenting a very culturally-specific 
version of happiness - one influenced by North American traditions of expressive individualism (a term popularised by Bellah, Madsen, Sullivan, Swidler, \& Tipton (1996), and defined by Pope (1991, p.384) as the 'unmitigated reference to the value of the individual self') - as being both universal and perennial (Izquierdo, 2005).

Yet, while PP has tended to be somewhat mono-cultural, this does not mean that psychology more broadly has not engaged with cross-cultural differences in wellbeing; indeed, cross-cultural psychologists have for years explored the ways in which happiness and wellbeing are conceptualised and experienced across different cultural locations. However, one could argue that such research has not been sufficiently appreciated within PP. This failure is arguably, in part, a result of the nature of PP itself. When PP was first proposed, its stated aim was to redress a postulated negativity bias in what was pejoratively referred to as 'psychology as usual' (Seligman \& Csikszentmihalyi, 2000). The argument was that, whereas psychology had hitherto tended to endorse a deficit model of the person, PP would offer a new conceptual and disciplinary space where researchers could focus on topics like happiness and wellbeing; indeed, the subsequent success of PP arguably shows that there was a need for such a field, providing a 'collective identity' for scholars interested in the 'brighter sides of human nature' (Linley \& Joseph, 2004, p.4). However, to create and sustain the idea of a new substantive field, its founders had to position it as indeed a new field, sufficiently different to what had preceded it in psychology to warrant its creation. As a result, critical theorists such as Lazarus (2003) and Held (2004) pointed to what they regarded as a 'separatist' agenda in PP, in which efforts were made to distance the field from related areas of enquiry, presenting it as different and/or better. This included seeking to differentiate PP from antecedent paradigms that were also interested in wellbeing and fulfilment, e.g., arguing that PP held an edge over humanistic psychology through $\mathrm{PP}^{\prime} \mathrm{s}$ emphasis on scientific enquiry (disregarding a fair amount of empirical work within humanistic psychology). One could argue that this type of separatism has caused scholars within PP to similarly overlook the wealth of theory and research pertaining to wellbeing in crosscultural psychology.

So, this paper attempts to open up a dialogue - or a bridge, or point of intersection - between $\mathrm{PP}$ and cross-cultural psychology by introducing the idea of 'positive cross-cultural psychology' (PCCP). This is conceived of as a disciplinary space where the two fields meet, comprising research on the cross-cultural dimensions of wellbeing, and undertaken by all scholars, whether they align themselves with PP or cross-cultural psychology or indeed any other relevant field (e.g., economics). This will enable PP to appreciate and draw on existing work on wellbeing in cross-cultural psychology, thereby helping PP to develop an understanding of wellbeing that is broader, more comprehensive and less culturally-specific (i.e., less based on Western conceptions and discourses). The idea of ' $\mathrm{PCCP}$ ' also reflects an emergent strand of work already in PP, in which scholars who align themselves with the field are increasingly beginning to investigate the cross-cultural dimensions of wellbeing, as epitomised by the pioneering efforts of Ed Diener and Robert Biswas-Diener. This emergent cross-cultural focus in the field has been driven by numerous factors, which include the global perspective of scholars such as Ed Diener, a response to critiques of the field's earlier presumptions of Western-oriented universality and the global dissemination of PP itself (i.e., how the field has been embraced and developed by scholars outside the West).

This paper aims to provide a brief overview of work that could be identified as pertaining to PCCP, showing the richness and vitality of research and theory in this area. In doing so, the paper will suggest that within such work - and indeed in academia and society more broadly - there are two broad currents of thought regarding 'other' cultures. The first, arguably more dominant 
and prevalent, is what we might call a 'universalising' perspective, which focuses on the commonalities between people across cultures. The second, perhaps currently less common or influential in PP, could be named the 'relativising' perspective, which focuses on the differences between people of different cultures. These terms derive from the work of Berry, Poortinga, Segall, and Dasen (2011), who identified four main perspectives in cross-cultural scholarship: extreme relativism; moderate relativism; moderate universalism; and extreme universalism (referred to as 'absolutism' in previous editions of their work). However, Berry et al. suggest that, in practice, it is rare to find scholars who endorse the extreme perspectives, with most work tending towards the moderate stances. Indeed, Berry, Poortinga, Segall, and Dasen (2002, p.xix) sometimes simply differentiate between universalist and relativist scholarship (which they also refer to respectively as 'culture-comparative' and 'culturalist' approaches). Following their example, this paper will aggregrate work into universalist and relativist perspectives (while recognising that each branch may contain both moderate and extreme varieties).

After this introduction, the first main section of the paper identifies work that leans towards a universalising perspective. This work seeks to identify universal aspects of psychological functioning, possessed irrespective of cultural location. Such work often involves gathering data from 'many people in many cultures,' as Triandis (2000, p.186) puts it, highlighting how people globally share similarities across a spectrum of human processes, from personality (Yamagata et al., 2006) to emotional expression (Ekman et al., 1987) to cognitive development (McBride-Chang \& Kail, 2002). In PP, research along these lines tends to involve global surveys, leading to the identification of 'contextual determinants' that influence happiness, from income to social capital. Crucially, although the presence and extent of these determinants differs from place to place, what makes this work universalist is that these factors are seen as reliably affecting wellbeing regardless of cultural context. For example, Diener and Seligman (2004) showed that being homeless is strongly detrimental to wellbeing, whether in Calcutta or California (since homeless people in these locales were both found to have comparably low levels of life satisfaction); as such, while societies across the world vary in their levels of homelessness, people will reliably be adversely affected by being homeless wherever they are. Thus, such work upholds to some extent, either implicitly or explicitly, the idea of a universal human nature, as despite apparent cultural differences, people are viewed as largely sharing similar needs and concerns.

The second section of the paper identifies work that leans towards a more relativising perspective. As well as drawing on the work of cross-cultural psychologists - since cross-cultural psychology encompasses both universalist and relativist stances - such scholarship also features those who specifically identify themselves as 'cultural' or 'indigenous' psychologists; Triandis (2000) defines the former as those who 'study a culture intensively with ethnographic methods' (p.186), and the latter as scholars who explore 'keywords, concepts, or categories that are widely used in a culture, and describe their meaning' (p.185). In PP, this approach has arguably been less prevalent than the universalising perspective, since the field has tended to be dominated by more conventional epistemological perspectives (such as positivism). However, we are starting to see emergent efforts in the field to investigate variation in the way different cultures relate to happiness and wellbeing, including in terms of how these are defined (Joshanloo, 2014), experienced (Uchida \& Ogihara, 2012) and reported (Oishi, 2010). Thus, works cited here as examples of this perspective pay close attention to cultural differences, and tend to argue that people's experiences of wellbeing, and of life more broadly, are strongly constituted by their cultural context. 
Finally, the third section of the paper presents a synthesising perspective, referred to as 'universal relativism,' which essentially describes a middle ground between universalism and relativism. It will be argued that many cross-cultural scholars (and their studies) actually tread this middle ground, acknowledging universals in human nature, but also recognising that these can be shaped by cultural context. It is worth noting that this concept of universal relativism could be regarded as fitting Berry et al.'s (2011) definition of moderate universalism, namely work that 'emphasises that there exist both differences and similarities in behaviour across cultures' (p.8). However, following Gardner and Oswald (2007), it may be preferable to describe this position as a synthesis of universalism and relativism. (Gardner and Oswald's own term for such a synthesis is 'universal pluralism'; however, this paper shall use the phrase 'universal relativism' to stay consistent with Berry et al.'s (2011) terminology.) Indeed, Berry et al. (2002, p.xix) appear to have argued for the desirability of such a synthesis, as they lament the fact that much of the discussion in cross-cultural scholarship has been 'dominated' by the debate between relativist and universalist approaches. This paper then aims to elucidate such a synthesis, in this case specifically with regard to cross-cultural scholarship pertaining to happiness and wellbeing.

\section{Universalism}

We begin by looking at what is perhaps the dominant cross-cultural trend within PP, the universalism perspective (which is generally of the moderate variety, per Berry et al.'s (2011) terminology, but which also includes the occasional extreme stance). This perspective is predicated on the notion that, beneath apparent cultural differences, people share a common human nature: while it is recognised that cultures/societies ${ }^{1}$ vary, people generally are not seen to, and so are viewed as responding to this variation in broadly similar ways. As such, research in this area - undertaken mainly by obtaining 'data from many people in many cultures' (Triandis, 2000, p.186), e.g., through large-scale surveys - examines the 'contextual factors' that impinge upon wellbeing, and then assesses the extent to which societies differ in terms of the presence or absence of these factors. (Again, just to emphasise, the reason this approach still merits the label 'universalist' is that people in these different cultures are conceptualised in a universal way as being similar, e.g., sharing common needs). For example, if poverty reliably hinders life satisfaction, then researchers can explain cross-cultural differences in wellbeing according to variations in poverty levels across countries (Lund et al., 2010). So, what are these factors? One of the most prominent sources of information on these comes from the long-running World Values Survey, which reveals extensive commonalities across diverse cultural and geographical locations. Helliwell (2003) and Helliwell and Putnam (2004) analysed three successive waves of this survey (spanning 1980 to 1997), covering over 87,000 people across 46 countries, looking for the most prominent contextual determinants of subjective wellbeing (SWB, e.g., life satisfaction). Their analysis found that the top five factors, ranked in terms of importance, were: family relationships; financial situation; work; community and friends; and health. Their analysis provides the structure for this section, which will highlight cross-cultural empirical work that is relevant to each of these factors.

\footnotetext{
${ }^{1}$ Although these terms are often used interchangeably, a useful distinction is offered by Wilber (2000). While both pertain to the way human beings exist within collective networks, culture refers to the 'intersubjective' aspects of those networks, and society to their 'interobjective' dimensions. Thus, culture describes how a group of people may share common 'intersubjective' values, meanings, worldviews, language, etc. Conversely, society pertains to the 'interobjective' structural features of such networks, i.e., objectively measurable factors such as income or employment levels. This usage will be employed here.
} 
Before exploring these contextual determinants, it will help to set these in perspective by outlining the theoretical terrain that underpins much of the discussion in this area. Many such universalising analyses draw on 'telic' theories of need satisfaction in which SWB is the result of the environment satisfying the person's basic biopsychosocial needs. According to Veenhoven (e.g., 2013), SWB thus depends on both 'liveability' (a congenial environment) and 'life-ability' (the ability of a person to take advantage of this). Early models of needs were hierarchical (e.g., Maslow, 1943), in which as lower levels are satisfied, higher ones assume prominence. However, the idea of hierarchy has been questioned; for instance, if material needs are not satisfied, people may still be sustained by supportive relationships, since such support may 'to some extent avert the psychological costs of material deprivation' (Biswas-Diener \& Diener, 2009, p.202). Consequently, non-hierarchical models have been proposed. For example, Lindenberg and Frey's (1993) social production function theory - see Lindenberg (2013) for a recent commentary - outlines two ultimate goals (physical and social wellbeing) and five instrumental goals (comfort, stimulation, status, behavioural confirmation and affection). Likewise, Doyle and Gough (1991) identify eleven intrinsically important 'universal satisfier characteristics' - from adequate nutritional food and water to security in childhood - the deprivation of which detrimentally impacts upon wellbeing.

So, having briefly introduced some of the prominent theorising that underpins much of the work within the universalising approach, we can turn to the contextual determinants themselves. According to Helliwell (2003) and Helliwell and Putnam's (2004) analyses of the World Values Survey, the most important factor for SWB is close, loving relationships, and marriage in particular. This finding is borne out by other studies. For example, a survey of 59,000 people in 42 countries found a consistent relationship between marital status and SWB (Diener, Gohm, Suh, \& Oishi, 2000). Conversely, the greatest depressant of wellbeing is separation, followed by widowhood (Blanchflower \& Oswald, 2004). The impact of relationships can be accounted for in terms of the telic theories above, where it is presented as a universal need (e.g., Maslow, 1943). More functionally, partnerships offer 'protection effects' which impact upon wellbeing, such as division of labour, and emotional support/companionship from people sharing similar goals and ideals (Arrindell \& Luteijn, 2000). However, we can note here that the positive impact of relationships can be mediated by cultural context; for example, there are greater social costs to being unmarried in cultures where marriage is a norm (Vanassche, Swicegood, \& Matthijs, 2013); similarly, the negative impact of separation and widowhood are mediated by intersubjective factors, such as the cultural status of widows (Lloyd-Sherlock, Corso, \& Minicuci, 2015). Thus, as we explore below in the third section on 'universal relativism,' universal needs (e.g., relationships) may intertwine with culturally-specific factors in complex ways.

The second factor is income. Cross-culturally, income has a weak correlation with wellbeing of around .2 (Lucas \& Schimmack, 2009). However, this correlation is itself mediated by wealth, with a trend of diminishing marginal returns (Blanchflower \& Oswald, 2004). At the lower end of the income scale, there is a robust association between the overall wealth of a country and its average wellbeing. A review of 115 studies across 33 countries by Lund et al. (2010) showed that, cross-culturally, poverty consistently has a detrimental impact on wellbeing, since it hinders basic needs being met (via lack of education, food insecurity, poor housing, financial worries, and environmental stressors). Here we see the relevance of the third factor, work; being in work reliably increases SWB, while unemployment is one of the strongest depressants of wellbeing (Wanberg, 2012). Thus, poverty and unemployment combine to adversely affect SWB. As poorer countries become wealthier, their overall levels of SWB tend to rise, since greater wealth enables citizens to increasingly satisfy their basic needs. However, once wealth rises above a certain 
point, further increases appear to be no longer matched by comparable rises in SWB, a phenomenon known as the Easterlin (2001) paradox (see Easterlin, 2015, for a recent commentary). (That said, debates on the validity of this interpretation continue; for instance, Veenhoven and Vergunst (2014) argue that the paradox itself is an 'illusion,' and that increasing prosperity does reliably enhance wellbeing.) One explanation for the apparent paradox is that as people rise out of poverty, they are more affected by relative than absolute income (Wolbring, Keuschnigg, \& Negele, 2013). Moreover, wealthier countries tend to have greater levels of income inequality within them, which has a detrimental effect on overall wellbeing; for example, Pickett and Wilkinson (2015) argue that societal inequality has a causal impact on social and health problems, such as higher morbidity and mortality rates, poorer educational performance, and greater levels of mental illness.

Unequal societies also tend to perform poorly on the fourth contextual determinant - social capital (defined by Bourdieu (1986, p.248) as 'the sum total of the resources, actual or virtual, that accrue to an individual (or a group) by virtue of being enmeshed in a durable network of more or less institutionalized relationships of mutual acquaintance and recognition'). For instance, comparing states within the USA, de Vries, Gosling, and Potter (2011) corroborated the idea that inequality leads to people being more competitive and antagonistic - as highlighted by Wilkinson and Pickett (2010) in their influential text The Spirit Level, and confirmed by Pickett and Wilkinson (2015) - observing a consistent association between levels of 'agreeableness' and state level inequality. Cross-culturally, social capital has a strong impact upon health and wellbeing (Helliwell, 2006). This is borne out in a Finnish study comparing a Finnish-speaking majority population with a Swedish-speaking minority (Hyyppä \& Mäki, 2003). Although the two communities are very similar in most respects (including genetic profile, socioeconomic status, education, use of health services, and ecological context), there are remarkable disparities in morbidity, disability and mortality. For example, from 1991 to 1996, the average age at death for Swedish-speaking men was 77.9, against 69.2 for Finnish-speaking men. The authors suggest that these dramatic health inequalities cannot be explained by conventional health-related risk factors, but derive from much greater levels of social capital among the Swedish-speaking minority (including voluntary associational activity, friendship networks, and religious involvement). As for why there are higher levels of social capital for the Swedish minority, this is possibly related to cultural differences, which - as indicated above - are accounted for by the universal relativism paradigm outlined in the third section below.

Finally, the fifth most important contextual determinant of SWB is health. Universally, disease and illness are found to detrimentally impact upon emotional wellbeing (see Arokiasamy et al. (2015) for a recent review). Likewise, Grant, Wardle, and Steptoe (2009) report that SWB is cross-culturally associated with common health behaviours (such as refraining from smoking). However, cross-cultural analyses reveal an unequal burden of disease across the world, with a greater risk of many illnesses in less developed countries. For example, in 2013 approximately 5.6 million children (under 5) died, 50\% of whom lived in sub-Saharan Africa (Liu et al., 2015). This is partly due to the greater prevalence of particular diseases in sub-Saharan African countries. It is also because similar illnesses have differential effects depending on location; for example, Deaton and Tortora (2015) argue that the prevalence of and prognosis for HIV/AIDS is much worse in poor countries - particularly in sub-Saharan Africa, which has the lowest global ratings for satisfaction with healthcare - due to intersecting social factors, including poverty, political instability, and weak healthcare infrastructure. Similarly, Knaul, Farmer, Bhadelia, Berman, and Horton (2015) point out that access to treatment and medicines is grossly inequitable; for instance, high-income countries account for less than $15 \%$ of the global 
population, but $94 \%$ of worldwide morphine consumption. This latter point highlights the intersecting issues addressed in this paper. People's wellbeing might be universally affected by a common factor (e.g., illness). Societies may then differ in terms of the extent to which their citizen's are exposed to this factor, but again, as per the universalising perspective, people may reliably respond to these societal differences in similar ways. However, some of these societal differences may themselves be driven by cultural factors; for instance, with HIV/AIDS, low takeup of preventative measures may be partly due to cultural beliefs relating to the aetiology of the disease (Penn \& Watermeyer, 2014). Work is beginning to emerge that takes account of such complexities, which could be deemed to fall within the universal relativism perspective outlined below. However, before considering this, the next section outlines the relativising trend, which focuses on the strong impact of cultural differences upon wellbeing.

\section{Relativism}

While the universalising stance is arguably the more dominant perspective in PP, in crosscultural psychology more broadly there is a wealth of research tending towards a relativising perspective. That said, we are increasingly seeing this perspective represented within PP itself; for instance, focusing on forgiveness in the Hmong culture, Sandage, Hill, and Vang (2003, p.564) argue for the desirability of developing a 'multicultural positive psychology'. As with the majority of scholars who lean towards the universalising stance above, scholars who adopt a relativist perspective are generally of the moderate variety in terms of Berry et al.'s (2011) terminology; but there are also some who tend towards extreme relativism. Most of the researchers included here would be likely to identify themselves as adhering to some form of social constructionism. Although this label encompasses a range of different perspectives, they all share the 'family resemblance' (Wittgenstein, 1953) of endorsing an epistemological perspective of anti-realism. Thus, in contrast to the more positivist stance of the universalising research considered in the previous section, anti-realism holds that distinctions used to represent and explain the world - e.g., PP constructs such as SWB - are socio-cultural products that reflect 'particular historical and cultural understandings,' rather than 'universal and immutable categories of human experience' (Bohan, 1996, p.xvi). Anti-realism comes in different 'strengths': strong constructionism holds that all aspects of human experience are entirely culturally created (and thus are particular to the specific cultural nexus in which they emerge), which obviously aligns with Berry et al.'s notion of extreme relativism; conversely, weak versions claim only that aspects of human experience are culturally shaped (but may be moulded from universal human needs and qualities), which is reflective of Berry et al.'s concept of moderate relativism. Either way, research of this relativising variety looks specifically at how people in different cultures may have significant differences concerning wellbeing, from the way it is conceptualised and defined (Joshanloo, 2014), to how it is experienced (Uchida \& Ogihara, 2012) and reported (Oishi, 2010).

Such cultural differences have been explored at various levels of scale. At the broadest level of cultural differences, the most prominent distinction in the cross-cultural literature is the notion that Western societies tend to be 'individualist', whereas Eastern cultures are 'collectivist' (Hofstede, 1980). While the distinction was originally developed to address differences at a societal level, Markus and Kitayama's (1991, p.224) work on self-construals explored the impact of such societal configurations on individual self-identity; this work suggested that people in the West tend to view themselves primarily as autonomous atomistic units, whereas Eastern cultures emphasise the 'fundamental relatedness of individuals,' highlighting the importance of 'attending to others, fitting in, and harmonious interdependence'; thus as Triandis (2001, p.907) 
puts it, people in collectivist cultures are more likely to 'define themselves as aspects of groups' and to 'give priority to in-group goals'. From a critical perspective, it could potentially be argued that this individualist-collectivist distinction is simply the latest incarnation of the 'East-West' orientalising discourse identified by Edward Said (1995); just as with the 'East-West' distinction itself, it arguably homogenises and obscures myriad differences at a local level, neglecting the fact that 'the East' possesses its own strains of individualism while 'the West' has its own collectivist traditions (Spiro, 1993). Nevertheless, the individualist-collectivist distinction has been analysed and somewhat corroborated in hundreds of empirical studies (Taras, Kirkman, \& Steel, 2010). And, in PCCP, the distinction does appear to capture important variation in the way wellbeing is shaped and experienced in different cultures. For example, Stavrova and Fetchenhauer (2015) show how wellbeing in collectivist cultures can be far more dependent upon the person successfully meeting approved social norms (e.g., in terms of sexual preferences or family structures).

However, as one imbues the spirit of the relativising approach, even the basic idea of comparing cultures on a measure like SWB becomes problematic. Interestingly, an influential advocate of the universalising stance in PP, the economist Lord Richard Layard (2005, p.33), raises this possibility, before dismissing it: 'Of course one could question whether the word for "happy" (or "satisfied") means the same thing in different languages. If it doesn't, we can learn nothing by comparing different countries. In fact it does.' It may not be so straightforward though. For example, a prominent notion in anthropology is the Sapir-Whorf hypothesis - from Sapir (1929) and his student Whorf (1940) - which holds that a culture's values and meanings are encoded in its language, such that linguistic categories shape and even determine thought itself. The critical question in terms of the legitimacy of making 'East-West' comparisons is whether terms such as 'happy' mean the same thing in different cultures. Crucially, Oishi (2010) suggests that they do not: whereas Western conceptions of happiness pertain essentially to a positive emotional state, in the East, happiness is taken as referring more to fortune and luck. This may be due to various interrelated reasons, including more 'fatalistic' cultural expectations (Shaw, 2011), deterministic philosophies derived from Hinduism and Buddhism, like the notion of karma (Guang, 2013), and greater self-effacement, leading people to attribute success to external factors (Imada \& Ellsworth, 2011). Moreover, even if happiness is defined similarly across cultures, there may be further methodological issues relating to variation in how it is reported; e.g., whereas people in individualist cultures may be encouraged to assert and celebrate individual achievements, those in collectivist cultures may feel pressure to be self-effacing (Du \& Jonas, 2015).

However, in the context of this relativizing perspective, even the notion of 'East-West' generalisations might be seen as too broad and simplifying, as noted above (Spiro, 1993). For example, work by cultural and indigenous psychologists has sought to understand cultural differences at a very fine-grained level, engaging with specific local cultures to examine their unique constructions and experiences of wellbeing, as per Sandage et al.'s (2003) analysis of the Hmong culture, cited above. Some of this work falls within the purview of PCCP (even if the scholars themselves would not identify as belonging to the field), since it pertains to happiness and wellbeing. For example, scholars have noted that certain cultures appear to lack words for particular mental states; according to Russell (1991), there is no word for sadness in the Tahitian or Chewong languages, no word for fear in Ifaluk, Utku, or Pintupi, and no word for surprise in Fore, Dani, or Malay. From the perspective of the Sapir-Whorf hypothesis, such absences imply that people in these cultures do not experience such states (or at least, do not do so widely or frequently enough to warrant the creation of words to represent them). Conversely, analyses of 
so-called 'untranslatable words' suggest that some emotion terms are specific to particular cultures, indicating that such emotions are particularly (or even uniquely) prominent in these cultures (Perlovsky, 2009). Thus, anthropologically-minded researchers have conducted indepth ethnographies of local cultures in attempts to understand their unique perspectives. For example, Izquierdo (2005) studied the Matsigenka tribe in the Peruvian Amazon. In contrast to the individualistic way in which happiness is arguably constructed in the West (and thus in conventional PP) - i.e., as a personal mental state over which the individual has a measure of control - the Matsigenka are portrayed as having a more 'holistic' understanding. Their sense of wellbeing has less to do with individual health and functioning, and is more related to the maintenance of a collective balance between the tribe and its physical and spiritual environment; as such, it is arguable that a person could not conceive of himself or herself as flourishing if the collective commons was in trouble (as indeed it was for the tribe), since the individual and the collective could not be meaningfully separated. Other scholars have conducted similarly finegrained analyses on constructions and experiences of wellbeing in other cultures, including the Bolivian Amazon (Reyes-García, 2012), Ladakh (Richard, 2014), ethnic Kyrgyz and Uzbeks in southern Kyrgyzstan (Borbieva, 2013), and Kazakhs in Western Mongolia (Werner, Barcus, \& Brede, 2013).

Similarly, other researchers have considered how culture influences the way in which ostensibly negative phenomena are experienced. For instance, studying the Pintupi tribe (Aborigines in the Australian Western desert), Myers (1988) reported that anger was deemed an acceptable state, particularly if in response to another person failing to be compassionate. The tribe placed great emphasis on a sense of shared identity/kinship with others, and thus breaking this kinship (through lack of compassion) was deemed to warrant a harsh response. Likewise, with the Ifaluk tribe (an atoll in Micronesia), Lutz (1987) encountered the notion of Song, a culturally valued state of 'justified anger'. Here, while anger may have had the same logical form as in other cultures (a desire for punishment based on perceived harm), its social meaning and valuation was different (i.e., highly positive). Conversely, in certain cultures, one can find some negative states given far greater weight, to the extent that there are specific culture-bound psychopathologies, referred to in the recent Diagnostic and Statistical Manual of Mental Disorders (DSM-V) as 'cultural concepts of distress' (see Kohrt et al. (2014) for a recent review). This does not simply mean cultural variation in how common disorders are experienced, but rather that sociocultural aspects of the disorder are inextricably connected to its underlying pathophysiology, and thus are defining features of it. For example, Taijin Kyofushu is a Japanese anxiety disorder involving a fear of offending others through awkward social behaviour or an imagined physical defect (Kirmayer, 1991). Kirmayer argues that this disorder is strongly culturally determined: not simply a cultural overlay of a universal condition, but rather a pathological amplification of culturally-specific concerns relating to norms of politeness and deference. Analyses such as this show the way in which mental experience can be strongly shaped by cultural context, and as such challenge the universalising studies cited above.

Relativising approaches are valuable for drawing our attention to complexity and nuance in different cultures, just as universalising approaches offer an important overview of common qualities shared by humanity. It is not the contention here that either perspective is flawed or inappropriate: we need to understand both common global trends (as universalism allows us to) and fine cultural details (as per relativism). However, it could be argued that, if either approach is pursued in isolation, one arrives at a skewed understanding of cross-cultural phenomena. Here, we might draw on the work of philosopher Ken Wilber (2000), who contends that particular paradigms or approaches can be partially true: their insights or understandings may be valid, but 
are nevertheless incomplete. Thus, if PP embraced only universalism, while it would rightly gain an appreciation of people's common humanity, it would overlook very real cultural differences. Conversely, if it tended only towards relativism, while it would develop a fine-grained understanding of the impact of culture on wellbeing, cross-cultural similarities would remain unappreciated. Given this analysis, there is value in trying to combine the two perspectives, as the final section illustrates.

\section{Universal Relativism}

So far this paper has set out two broad trends within PCCP: a universalising stance that looks for commonalities between people of different cultures, and a relativistic perspective focused on particularity, pluralism and difference. However, the two perspectives might not necessarily be mutually exclusive. Following a Hegelian process of dialectic, if the universalising stance is the thesis, and the relativising perspective represents its antithesis, it is possible to discern work that aims towards a synthesis of the two. Indeed, it could be argued that most work in PCCP actually falls within this synthesising middle ground. The notion of such a synthesis has already been identified by Gardner and Oswald (2007) under the rubric of 'universal pluralism'. Indeed, Berry et al.'s (2011) concept of moderate universalism comes close to acknowledging this kind of synthesis; however, rather than the synthesising flavour of work in this area being viewed as a weak form of universalism, such research is arguably better captured by the hybrid term 'universal relativism'. Essentially, work that falls under the banner of universal relativism recognises that it is possible to acknowledge both universal similarities and cultural diversity, doing so by differentiating between deep versus surface structures (both within people and within cultures) (see e.g., Wilber, 1996, p.46). The notion of deep structures refers to the way in which people may be seen as having universal needs, e.g., as per Maslow (1943). Societies then develop deep structural systems designed to meet these needs, including housing (to meet safety needs), laws (to meet security needs), systems of mutual recognition, e.g., names (to meet esteem needs), relationship structures, e.g., marriage (to meet love needs), and value systems, e.g., religion and philosophy (to meet meaning needs). However, while these deep structures may be universal, they can be expressed at a surface level in an almost infinite variety of ways, whether by people themselves or by their culture more broadly. Crucially, this does not mean a superficial cultural overlay, but very significant differences in expression that fundamentally change the way in which these needs are experienced and met. This notion of universal relativism is represented visually in figure 1 below; this model suggests that the impact on wellbeing of the universal contextual determinants (from family relationships to health) is mediated by diverse processes and phenomena (from tradition to geography) that are specific to particular cultural contexts.

As one considers the literature within PCCP, it is possible to discern this universal relativism approach being quite widely endorsed (even if the authors themselves do not use such a term). Indeed, many of the researchers cited above as producing work illustrative of a universalising or relativising stance have also undertaken research that could be categorised as reflecting a universal relativism approach. As Berry et al. (2011) point out, it is rare to find scholars promulgating an 'extreme' position of pure universalism or relativism; most researchers are thus 'moderates' who acknowledge the validity of both universalism and relativism, and hence who could broadly be said to align with a position of universal relativism.) We can see this kind of universal relativism in studies which analyse the contextual determinants of wellbeing - and thus which align with the universalising stance - but which at the same time consider cultural differences that moderate the way such determinants are experienced. In terms of relationships 
for example, the first determinant identified by Helliwell (2003) and Helliwell and Putnam (2004), marriage, might be of greater benefit to people in more individualist cultures than to those in collectivist ones, since the generally lower levels of social support in individualist cultures means that the relative impact of close relationships may be greater (Kasser \& Ahuvia, 2002). In terms of the second factor, income, while it may universally be the case that this matters for wellbeing (at least until one's basic needs are met), cultural value systems can play a significant role in the weight and importance attached to money. Take, for example, materialism, defined as 'a set of centrally held beliefs about the importance of possessions in one's life' (Richins \& Dawson, 1992, p.308). On the whole, materialism is cross-culturally negatively correlated with SWB (Platz \& Hyman, 2013). And yet crucially, from the universal relativism perspective, there are differences in the extent to which different cultures are materialistic, with Western countries often regarded as more materialistic (Joshanloo, 2013). (That said, Podoshen, Li, and Zhang (2011) take issue with this generalisation, arguing that rapid socio-economic change in Eastern countries is leading to increased materialistic consumer capitalism in these regions.) Such 'relativising' differences in culture complicate the 'universal' relationship between income and wellbeing in interesting ways.

Figure 1: Diagram showing universal factors and relativistic meditators of wellbeing

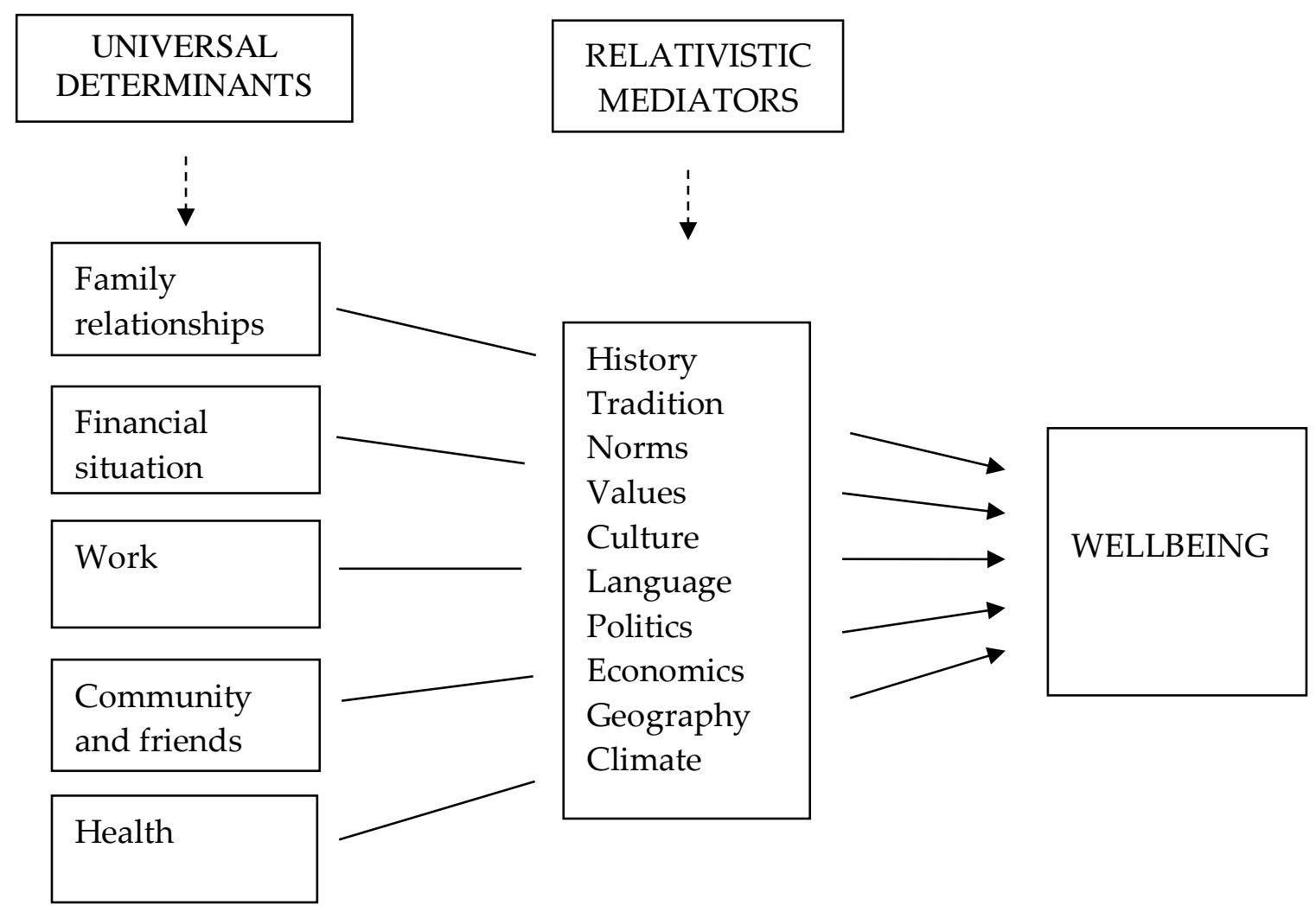

Moving on to the third factor, work, while unemployment is generally (i.e., universally) detrimental to SWB (Bell \& Blanchflower, 2010), researchers have explored the moderating 'relativising' effect of culturally-specific factors. For instance, analysing the 2010 European Working Conditions Survey, Bambra, Lunau, Van der Wel, Eikemo, and Dragano (2014) found that while unemployment reliably lowered health and wellbeing, its impact was strongly mediated by the nature of the welfare regime in each country. Returning to the individualistcollectivist distinction, research has suggested that unemployment may be less easy to bear in 
individualist cultures, as people are more likely to be judged based on individual achievements, and/or may have less social support to cushion its impact (Martella \& Maass, 2000). Unemployment is perhaps also more difficult to deal with in cultures characterised by a strong work ethic, where lack of work tends to be more harshly penalised as deviation from the norm (Stam, Sieben, Verbakel, \& de Graaf, 2015). With the fourth factor, social capital, it is almost axiomatic that social capital is higher in collectivist cultures, since these are defined by their close social bonds (Triandis, 2001). However, there may be paradoxical complexities in this general trend. In a survey of 28 countries, Kappes, Sharma, and Oettingen (2013) found a significant positive correlation between individualism and interpersonal trust (an aspect of social capital). One explanation is that in individualist countries, people are less enmeshed in tight culturallybound in-groups; this means that they tend to engage more with the 'general population,' and thus are less wary of members of the out-group. Likewise, Allik and Realo (2004) report that in more individualistic countries there is a higher level of civic engagement in political activity, possibly because once close personal networks become eroded, it becomes necessary to develop politically-driven societal structures (such as the welfare state) to take their place.

In discussing the relevance of political structures to wellbeing - and cultural variation in such structures - we might end here by considering one final contextual determinant: freedom. While this was not ranked in the top five by Helliwell (2003) and Helliwell and Putnam (2004), they did highlight its universal importance. Indeed, PP recognises self-determination, and its constituent elements, as a universal human need (Ryan \& Deci, 2000). Crucially however, socio-cultural structures strongly impact upon people's ability to attain self-determination, and consequently national wellbeing is linked to 'political and cultural value supports for self-determination' (Downie, Koestner, \& Chua, 2007, p.174). Societies vary in the extent to which they facilitate various freedoms, including personal freedom (freedom of action, thought, and association; Ruger \& Sorens, 2009), political freedom (liberal democracy, and checks and balances limiting the state's powers; Neumann, 1953), and economic freedom (personal choice, and protection of private property; Graeff \& Mehlkop, 2003). All these freedoms are affected by the quality of political-legal frameworks, which vary greatly across countries; thus, communities with the highest SWB tend to be those that enjoy 'effective social and political institutions' (Duncan, 2010, p.165). In this regard, the World Bank has conducted extensive assessments of the quality of governance worldwide (Kaufmann, Kraay, \& Mastruzzi, 2009). Based on over 350 variables, six main 'aggregate governance indicators' have been identified, capturing six key dimensions of institutional quality of governance. These include: voice and accountability (i.e., political, civil, and human rights); stability and lack of violence; government effectiveness (bureaucratic competence and quality of public services); the regulatory framework (market-friendly policies); rule of law (quality of policing and the legal system); and control of corruption.

Thus, with this last point, we see the complex intersections between a universal human need (in this case, freedom) and socio-cultural variation (in how freedom is valued and upheld). Given these complex intersections, we can discern the value of the universal relativism approach. Firstly, freedom can be recognised as a universal need. This differs from the strong forms of social constructionism that are characteristic of the extreme relativism perspective (and even some moderate varieties of it), which often deny the existence of any such universals. For example, some people adopting a constructionist stance may embrace the kind of strong cultural relativism which holds that a belief in individual freedom is particular to Western cultures, and should not be generalised (Donnelly, 1984). However, the universal relativism approach still recognises that cultures have a strong determining impact on the way in which needs such as freedom are conceptualised, defined, valued, upheld and promoted. Such differences are not a superficial 
cultural overlay, but have a deep impact on how people experience a phenomenon like freedom, and hence have a significant mediating effect on the (universal) connection between such contextual determinants and wellbeing. This type of approach thus potentially offers the best of both worlds, a nuanced synthesis of the two dominant trends in cross-cultural psychology. One might argue that the field of PP would benefit from embracing a stance of universal relativism, allowing it to fully appreciate the breadth of extant empirical and theoretical work in crosscultural psychology, as well as offering an agenda for research in the years ahead.

\section{Acknowledgments}

The author would like to thank recent students on the MSc in Applied Positive Psychology programme at the University of East London, whose debates and questions in class helped provide inspiration for this paper. The author would also like to thank the anonymous reviewers and the editors at the International Journal of Wellbeing for their constructive comments on the paper.

\section{Authors}

Tim Lomas

University of East London

t.lomas@uel.ac.uk

\section{Publishing Timeline}

Received 14 May 2015

Accepted 26 September 2015

Published 18 December 2015

\section{References}

Allik, J., \& Realo, A. (2004). Individualism-collectivism and social capital. Journal of Cross-Cultural Psychology, 35(1), 29-49. http://dx.doi.org/10.1177/0022022103260381

Arokiasamy, P., Uttamacharya, U., Jain, K., Biritwum, R. B., Yawson, A. E., Wu, F., . . Rodríguez, A. S. (2015). The impact of multimorbidity on adult physical and mental health in low-and middle-income countries: What does the study on global ageing and adult health (SAGE) reveal? BMC Medicine, 13(1), 178. http://dx.doi.org/10.1186/s12916-015-0402-8

Arrindell, W. A., \& Luteijn, F. (2000). Similarity between intimate partners for personality traits as related to individual levels of satisfaction with life. Personality and Individual Differences, 28(4), 629-637. http://dx.doi.org/10.1016/S0191-8869(99)00125-7

Bambra, C., Lunau, T., Van der Wel, K. A., Eikemo, T. A., \& Dragano, N. (2014). Work, health, and welfare: The association between working conditions, welfare states, and self-reported general health in Europe. International Journal of Health Services, 44(1), 113-136. http://dx.doi.org/10.2190/HS.44.1.g

Bell, D. N., \& Blanchflower, D. G. (2010). Recession and Unemployment in the OECD. Paper presented at the CESifo Forum.

Bellah, R. N., Madsen, R., Sullivan, W. M., Swidler, A., \& Tipton, S. M. (1996). Habits of the heart: Individualism and commitment in American life. Berkeley, CA: University of California Press.

Berry, J. W., Poortinga, Y. H., Segall, M. H., \& Dasen, P. R. (2002). Cross-cultural psychology: Research and applications (2nd ed.). Cambridge: Cambridge University Press.

Berry, J. W., Poortinga, Y. H., Segall, M. H., \& Dasen, P. R. (2011). Cross-cultural psychology: Research and applications (3rd ed.). Cambridge: Cambridge University Press. http://dx.doi.org/10.1017/CBO9780511974274

Biswas-Diener, R., \& Diener, E. (2009). Making the best of a bad situation: Satisfaction in the slums of Calcutta. In E. Diener (Ed.), Culture and well-being (Vol. 38, pp. 261-278): Springer Netherlands. http://dx.doi.org/10.1007/978-90-481-2352-0_13 
Blanchflower, D. G., \& Oswald, A. J. (2004). Well-being over time in Britain and the USA. Journal of Public Economics, 88(7-8), 1359-1386. http://dx.doi.org/10.1016/S0047-2727(02)00168-8

Bohan, J. (1996). The psychology of sexual orientation: Coming to terms. New York: Routledge.

Borbieva, N. O. N. (2013). Anxiety, order and the other: Well-being among ethnic Kyrgyz and Uzbeks. Central Asian Survey, 32(4), 501-513. http://dx.doi.org/10.1080/02634937.2013.863915

Bourdieu, P. (1986). The forms of capital. In J. G. Richardson (Ed.), Handbook of theory and research for the sociology of education (pp. 241-258). New York: Greenwood.

de Vries, R., Gosling, S., \& Potter, J. (2011). Income inequality and personality: Are less equal U.S. states less agreeable? Social Science \& Medicine, 72(12), 1978-1985.

http://dx.doi.org/10.1016/j.socscimed.2011.03.046

Deaton, A. S., \& Tortora, R. (2015). People in sub-Saharan Africa rate their health and health care among the lowest in the world. Health Affairs, 34(3), 519-527. http://dx.doi.org/10.1377/hlthaff.2014.0798

Diener, E., Gohm, C. L., Suh, E., \& Oishi, S. (2000). Similarity of the relations between marital status and subjective well-being across cultures. Journal of Cross-Cultural Psychology, 31(4), 419-436. http://dx.doi.org/10.1177/0022022100031004001

Diener, E., \& Seligman, M. E. P. (2004). Beyond money: Toward an economy of well-being. Psychological Science in the Public Interest, 5(1), 1-31. http://dx.doi.org/10.1111/j.0963-7214.2004.00501001.x

Donnelly, J. (1984). Cultural relativism and universal human rights. Human Rights Quarterly, 6(4), 400419. http://dx.doi.org/10.2307/762182

Downie, M., Koestner, R., \& Chua, S. (2007). Political support for self-determination, wealth, and national subjective well-being. Motivation and Emotion, 31(3), 174-181. http://dx.doi.org/10.1007/s11031-0079070-0

Doyle, L., \& Gough, I. (1991). A theory of human need. London: Macmillan.

Du, H., \& Jonas, E. (2015). Being modest makes you feel bad: Effects of the modesty norm and mortality salience on self-esteem in a collectivistic culture. Scandinavian Journal of Psychology, 56(1), 86-98. http://dx.doi.org/10.1111/sjop.12175

Duncan, G. (2010). Should happiness-maximization be the goal of government? Journal of Happiness Studies, 11(2), 163-178. http://dx.doi.org/10.1007/s10902-008-9129-y

Easterlin, R. A. (2001). Income and happiness: Towards a unified theory. The Economic Journal, 111(473), 465-484. doi: 10.1111/1468-0297.00646

Easterlin, R. A. (2015). Happiness and economic growth: The evidence. Netherlands: Springer.

Ekman, P., Friesen, W. V., O'Sullivan, M., Chan, A., Diacoyanni-Tarlatzis, I., Heider, K., ... Tzavaras, A. (1987). Universals and cultural differences in the judgments of facial expressions of emotion. Journal of Personality and Social Psychology, 53(4), 712-717. http://dx.doi.org/10.1037/0022-3514.53.4.712

Gardner, J., \& Oswald, A. J. (2007). Money and mental wellbeing: A longitudinal study of medium-sized lottery wins. Journal of Health Economics, 26(1), 49-60. http://dx.doi.org/10.1016/j.jhealeco.2006.08.004

Graeff, P., \& Mehlkop, G. (2003). The impact of economic freedom on corruption: Different patterns for rich and poor countries. European Journal of Political Economy, 19(3), 605-620. http://dx.doi.org/10.1016/S0176-2680(03)00015-6

Grant, N., Wardle, J., \& Steptoe, A. (2009). The relationship between life satisfaction and health behavior: A cross-cultural analysis of young adults. International Journal of Behavioral Medicine, 16(3), 259-268. http://dx.doi.org/10.1007/s12529-009-9032-x

Guang, X. (2013). Buddhist impact on Chinese culture. Asian Philosophy, 23(4), 305-322. http://dx.doi.org/10.1080/09552367.2013.831606

Held, B. S. (2004). The negative side of positive psychology. Journal of Humanistic Psychology, 44(1), 9-46. http://dx.doi.org/10.1177/0022167803259645

Helliwell, J. F. (2003). How's life? Combining individual and national variables to explain subjective wellbeing. Economic Modelling, 20(2), 331-360. http://dx.doi.org/10.1016/S0264-9993(02)00057-3

Helliwell, J. F. (2006). Well-being, social capital and public policy: What's new?*. The Economic Journal, 116(510), C34-C45. http://dx.doi.org/10.1111/j.1468-0297.2006.01074.x 
Helliwell, J. F., \& Putnam, R. D. (2004). The social context of well-being. Philosophical Transactions of the Royal Society of London. Series B: Biological Sciences, 359(1449), 1435-1446. http://dx.doi.org/10.1098/rstb.2004.1522

Hofstede, G. (1980). Culture's consequences: Comparing values, behaviors, institutions and organizations across nations. Beverly Hills, CA: Sage.

Hyyppä, M. T., \& Mäki, J. (2003). Social participation and health in a community rich in stock of social capital. Health Education Research, 18(6), 770-779. http://dx.doi.org/10.1093/her/cyf044

Imada, T., \& Ellsworth, P. C. (2011). Proud Americans and lucky Japanese: Cultural differences in appraisal and corresponding emotion. Emotion, 11(2), 329-345. http://dx.doi.org/10.1037/a0022855

Izquierdo, C. (2005). When "health" is not enough: Societal, individual and biomedical assessments of well-being among the Matsigenka of the Peruvian Amazon. Social Science \& Medicine, 61(4), 767-783. http://dx.doi.org/10.1016/j.socscimed.2004.08.045

Joshanloo, M. (2013). A comparison of Western and Islamic conceptions of happiness. Journal of Happiness Studies, 14(6), 1857-1874. http://dx.doi.org/10.1007/s10902-012-9406-7

Joshanloo, M. (2014). Eastern conceptualizations of happiness: Fundamental differences with western views. Journal of Happiness Studies, 15(2), 475-493. http://dx.doi.org/10.1007/s10902-013-9431-1

Kappes, H. B., Sharma, E., \& Oettingen, G. (2013). Positive fantasies dampen charitable giving when many resources are demanded. Journal of Consumer Psychology, 23(1), 128-135. http://dx.doi.org/10.1016/j.jcps.2012.02.001

Kasser, T., \& Ahuvia, A. (2002). Materialistic values and well-being in business students. European Journal of Social Psychology, 32(1), 137-146. http://dx.doi.org/10.1002/ejsp.85

Kaufmann, D., Kraay, A., \& Mastruzzi, M. (2009). Governance matters VIII: Aggregate and individual governance indicators, 1996-2008. World bank policy research working paper (4978). http://dx.doi.org/10.1596/1813-9450-4978

Kirmayer, L. J. (1991). The place of culture in psychiatric nosology: Taijin kyofusho and DSM-IIIR. Journal of Nervous and Mental Disease, 179(1), 19-28. http://dx.doi.org/10.1097/00005053-199101000$\underline{00005}$

Knaul, F. M., Farmer, P. E., Bhadelia, A., Berman, P., \& Horton, R. (2015). Closing the divide: The Harvard Global Equity Initiative-Lancet Commission on global access to pain control and palliative care. The Lancet, 386(9995), 722-724. http://dx.doi.org/10.1016/S0140-6736(15)60289-6

Kohrt, B. A., Rasmussen, A., Kaiser, B. N., Haroz, E. E., Maharjan, S. M., Mutamba, B. B., ... Hinton, D. E. (2014). Cultural concepts of distress and psychiatric disorders: literature review and research recommendations for global mental health epidemiology. International Journal of Epidemiology, 43(2), 365-406. http://dx.doi.org/10.1093/ije/dyt227

Layard, R. (2005). Happiness: Lessons from a new science. London: Penguin.

Lazarus, R. S. (2003). Does the positive psychology movement have legs? Psychological Inquiry, 14(2), 93109. doi: $10.2307 / 1449813$

Lindenberg, S. (2013). Social rationality, self-regulation, and well-being: The regulatory significance of needs, goals, and the self. In R. Wittek, T. Snijders \& V. Nee (Eds.), The handbook of rational choice social research (pp. 72-112). California: Stanford University Press. http://dx.doi.org/10.1177/000169939303600304

Lindenberg, S., \& Frey, B. S. (1993). Alternatives, frames, and relative prices: A broader view of rational choice theory. Acta Sociologica, 36(3), 191-205. doi: 10.1177/000169939303600304

Linley, P. A., \& Joseph, S. (2004). Applied positive psychology: A new perspective for professional practice. In P. A. Linley \& S. Joseph (Eds.), Positive psychology in practice (pp. 3-12). Hoboken, New Jersey: John Wiley and Sons. http://dx.doi.org/10.1002/9780470939338

Liu, L., Oza, S., Hogan, D., Perin, J., Rudan, I., Lawn, J. E., . . Black, R. E. (2015). Global, regional, and national causes of child mortality in 2000-13, with projections to inform post-2015 priorities: an updated systematic analysis. The Lancet, 385(9966), 430-440. http://dx.doi.org/10.1016/S01406736(14)61698-6 
Lloyd-Sherlock, P., Corso, B., \& Minicuci, N. (2015). Widowhood, socio-economic status, health and wellbeing in low and middle-income countries. The Journal of Development Studies, 1-15. http://dx.doi.org/10.1080/00220388.2015.1066497

Lucas, R. E., \& Schimmack, U. (2009). Income and well-being: How big is the gap between the rich and the poor? Journal of Research in Personality, 43(1), 75-78. http://dx.doi.org/10.1016/j.jrp.2008.09.004

Lund, C., Breen, A., Flisher, A. J., Kakuma, R., Corrigall, J., Joska, J. A., . . Patel, V. (2010). Poverty and common mental disorders in low and middle income countries: A systematic review. Social Science $\mathcal{E}$ Medicine, 71(3), 517-528. http://dx.doi.org/10.1016/j.socscimed.2010.04.027

Lutz, C. (1987). Goals, events, and understanding in Ifaluk emotion theory. In D. Holland \& N. Quinn (Eds.), Cultural models in language and thought (pp. 290-312). New York: Cambridge University Press. http://dx.doi.org/10.1017/CBO9780511607660.013

Markus, H. R., \& Kitayama, S. (1991). Culture and the self: Implications for cognition, emotion, and motivation. Psychological Review, 98(2), 224-253. http://dx.doi.org/10.1037/0033-295X.98.2.224

Martella, D., \& Maass, A. (2000). Unemployment and life satisfaction: The moderating role of time structure and collectivism. Journal of Applied Social Psychology, 30(5), 1095-1108. http://dx.doi.org/10.1111/j.1559-1816.2000.tb02512.x

Maslow, A. H. (1943). A theory of human motivation. Psychological Review, 50(4), 370-396. http://dx.doi.org/10.1037/h0054346

McBride-Chang, C., \& Kail, R. V. (2002). Cross-cultural similarities in the predictors of reading acquisition. Child Development, 73(5), 1392-1407. http://dx.doi.org/10.1111/1467-8624.00479

Myers, F. R. (1988). The logic and meaning of anger among Pintupi Aborigines. Man, 23(4), 589-610. http://dx.doi.org/10.2307/2802595

Neumann, F. L. (1953). The concept of political freedom. Columbia Law Review, 53(7), 901-935. http://dx.doi.org/10.2307/1119178

Oishi, S. (2010). Culture and well-being: Conceptual and methodological issues. In E. Diener, J. F. Helliwell \& D. Kahneman (Eds.), International differences in well-being (pp. 34-69). New York: Oxford University Press. http://dx.doi.org/10.1093/acprof:oso/9780199732739.003.0003

Penn, C., \& Watermeyer, J. (2014). Exploring cultural beliefs about "that sickness": Grandmothers' explanations of HIV in an urban South African context. Journal of the Association of Nurses in AIDS Care, 25(6), 508-519. http://dx.doi.org/10.1016/j.jana.2014.02.006

Perlovsky, L. (2009). Language and emotions: Emotional Sapir-Whorf hypothesis. Neural Networks, 22(56), 518-526. http://dx.doi.org/10.1016/j.neunet.2009.06.034

Pickett, K. E., \& Wilkinson, R. G. (2015). Income inequality and health: A causal review. Social Science \& Medicine, 128, 316-326. http://dx.doi.org/10.1016/j.socscimed.2014.12.031

Platz, J., \& Hyman, N. (2013). Mentorship. Clinics in Colon and Rectal Surgery, 26(4), 218-223. http://dx.doi.org/10.1055/s-0033-1356720

Podoshen, J. S., Li, L., \& Zhang, J. (2011). Materialism and conspicuous consumption in China: A crosscultural examination. International Journal of Consumer Studies, 35(1), 17-25. http://dx.doi.org/10.1111/j.1470-6431.2010.00930.x

Pope, S. (1991). Expressive individualism and true self-love: A Thomistic perspective. The Journal of Religion, 384-399. http://dx.doi.org/10.1086/488661

Reyes-García, V. (2012). Happiness in the Amazon: Folk explanations of happiness in a hunterhorticulturalist society in the Bolivian Amazon. In H. Selin \& G. Davey (Eds.), Happiness across cultures (pp. 209-225). Netherlands: Springer. http://dx.doi.org/10.1007/978-94-007-2700-7 15

Richard, B. O. (2014). Families, well-being, and inclusion: Rethinking priorities for children with cognitive disabilities in Ladakh, India. Childhood, 21(3), 308-323. http://dx.doi.org/10.1177/0907568214526264

Richins, M. L., \& Dawson, S. (1992). A consumer values orientation for materialism and its measurement: Scale development and validation. Journal of Consumer Research, 19(3), 303-316.

http://dx.doi.org/10.1086/209304

Ruger, W., \& Sorens, J. (2009). Freedom in the 50 states: An index of personal and economic freedom. SSRN 1354289. http://dx.doi.org/10.2139/ssrn.1354289 
Russell, J. A. (1991). Culture and the categorization of emotions. Psychological Bulletin, 110(3), 426-450. http://dx.doi.org/10.1037/0033-2909.110.3.426

Ryan, R. M., \& Deci, E. L. (2000). Self-determination theory and the facilitation of intrinsic motivation, social development, and well-being. American Psychologist, 55(1), 68-78. http://dx.doi.org/10.1037/0003-066X.55.1.68

Said, E. W. (1995). Orientalism: Western conceptions of the Orient. London: Penguin.

Sandage, S. J., Hill, P. C., \& Vang, H. C. (2003). Toward a multicultural positive psychology: Indigenous forgiveness and Hmong culture. The Counseling Psychologist, 31(5), 564-592. http://dx.doi.org/10.1177/0011000003256350

Sapir, E. (1929). The status of linguistics as a science. Language, 207-214. http://dx.doi.org/10.2307/409588

Seligman, M. E. P., \& Csikszentmihalyi, M. (2000). Positive psychology: An introduction. American Psychologist, 55(1), 5-14. http://dx.doi.org/10.1037/0003-066X.55.1.5

Shaw, J. (2011). Freedom: East and West. Sophia, 50(3), 481-497. http://dx.doi.org/10.1007/s11841-011-0237$\underline{5}$

Spiro, M. E. (1993). Is the Western conception of the self "peculiar" within the context of the world cultures? Ethos, 21(2), 107-153. http://dx.doi.org/10.1525/eth.1993.21.2.02a00010

Stam, K., Sieben, I., Verbakel, E., \& de Graaf, P. M. (2015). Employment status and subjective well-being: The role of the social norm to work. Work, Employment \& Society. http://dx.doi.org/10.1177/0950017014564602

Stavrova, O., \& Fetchenhauer, D. (2015). Single parents, unhappy parents? Parenthood, partnership, and the cultural normative context. Journal of Cross-Cultural Psychology, 46(1), 134-149. http://dx.doi.org/10.1177/0022022114551160

Taras, V., Kirkman, B. L., \& Steel, P. (2010). Examining the impact of culture's consequences: A threedecade, multilevel, meta-analytic review of Hofstede's cultural value dimensions. Journal of Applied Psychology, 95(3), 405-439. http://dx.doi.org/10.1037/a0018938

Triandis, H. C. (2000). Dialectics between cultural and cross-cultural psychology. Asian Journal of Social Psychology, 3(3), 185-195. http://dx.doi.org/10.1111/1467-839X.00063

Triandis, H. C. (2001). Individualism-collectivism and personality. Journal of Personality, 69(6), 907-924. http://dx.doi.org/10.1111/1467-6494.696169

Uchida, Y., \& Ogihara, Y. (2012). Personal or interpersonal construal of happiness: A cultural psychological perspective. International Journal of Wellbeing, 2(4), 354-369. http://dx.doi.org/10.5502/ijw.v2.i4.5

Vanassche, S., Swicegood, G., \& Matthijs, K. (2013). Marriage and children as a key to happiness? Crossnational differences in the effects of marital status and children on well-being. Journal of Happiness Studies, 14(2), 501-524. http://dx.doi.org/10.1007/s10902-012-9340-8

Veenhoven, R. (2013). The four qualities of life ordering concepts and measures of the good life. In A. Delle Fave (Ed.), The exploration of happiness (pp. 195-226). Netherlands: Springer. http://dx.doi.org/10.1007/978-94-007-5702-8 11

Veenhoven, R., \& Vergunst, F. (2014). The Easterlin illusion: Economic growth does go with greater happiness. International Journal of Happiness and Development, 1(4), 311-343. http://dx.doi.org/10.1504/IJHD.2014.066115

Wanberg, C. R. (2012). The individual experience of unemployment. Annual Review of Psychology, 63, 369396. http://dx.doi.org/10.1146/annurev-psych-120710-100500

Werner, C., Barcus, H., \& Brede, N. (2013). Discovering a sense of well-being through the revival of Islam: Profiles of Kazakh imams in Western Mongolia. Central Asian Survey, 32(4), 527-541. http://dx.doi.org/10.1080/02634937.2013.862966

Whorf, B. L. (1940). Science and linguistics. Technology Review, 42(6), 229-231, 247-248.

Wierzbicka, A. (2004). 'Happiness' in cross-linguistic \& cross-cultural perspective. Daedalus, 133(2), 34-43. http://dx.doi.org/10.1162/001152604323049370

Wilber, K. (1996). The Atman Project: A Transpersonal View of Human Development. Boston: Quest Books.

Wilber, K. (2000). Integral psychology. Boston: Shambhala. 
Wilkinson, R. G., \& Pickett, K. (2010). The spirit level: Why more equal societies almost always do better. London: Allen Lane.

Wittgenstein, L. (1953). Philosophical investigations. New York: Macmillan.

Wolbring, T., Keuschnigg, M., \& Negele, E. (2013). Needs, comparisons, and adaptation: The importance of relative income for life satisfaction. European Sociological Review, 29(1), 86-104.

http://dx.doi.org/10.1093/esr/jcr042

Yamagata, S., Suzuki, A., Ando, J., Ono, Y., Kijima, N., Yoshimura, K., . . Jang, K. L. (2006). Is the genetic structure of human personality universal? A cross-cultural twin study from North America, Europe, and Asia. Journal of Personality and Social Psychology, 90(6), 987-998. http://dx.doi.org/10.1037/0022$\underline{3514.90 .6 .987}$ 